\title{
1, 3, 5-Tris (2-hydroxyethyl) Isocyanurate Functionalized SBA-15 (THEIC-SBA-15): as a Novel Heterogeneous Nano-Catalyst for the One-Pot Three-Component Synthesis of Tetrahydrobenzo [b] Pyrans in Water
}

\author{
Alireza Rezazadeh Shendabadi ${ }^{1}$, Hamid Tebyanian ${ }^{2}\left(\mathbb{D}\right.$, Reza Zare ${ }^{3(\mathbb{D})}$, Mohammad G. Dekamin ${ }^{1(\mathbb{D})}$, \\ Hamid Kooshki 4 (D), Jamal Rashidiani 4, * (D) \\ 1 Department of Chemistry, Iran University of Science and Technology. P.O. Box 16846-13114, Tehran, Iran \\ 2 Research Center for Prevention of Oral and Dental Diseases, Baqiyatallah University of Medical Sciences, Tehran, Iran \\ 3 Faculty of Chemistry, Bu-Ali Sina University, Hamadan, Iran \\ 4 Nanobiotechnology Research Centre, Baqiyatallah University of Medical Science, Tehran, Iran \\ * Correspondence: jrashidiyani@gmail.com;
}

Scopus Author ID 55574933300

Received: 7.05.2020; Revised: 23.05.2020; Accepted: 24.05.2020; Published: 27.05.2020

\begin{abstract}
Tris (2-hydroxyethyl) isocyanurate functionalized SBA-15 is used as a novel, highly efficient, and recyclable heterogeneous nano-catalyst for the one-pot 3-component synthesis of tetrahydro benzo $[\mathrm{b}]$ pyran derivatives. These unique derivatives were synthesized through the condensation reactions of the enolizable compounds, different aldehydes, and malononitrile (or ethyl cyanoacetate) under the mild reaction conditions, in the short reaction times, and gives excellent yields in the refluxing $\mathrm{H}_{2} \mathrm{O}$ as a green solvent. The accuracy of synthesizing functionalized SBA-15 was confirmed with FT-IR spectroscopy. Then the catalyst was characterized by scanning electron microscopy (SEM), transition electron microscopy (TEM), and surface area analysis (BET). TEM images demonstrated that the synthesized catalyst had a hexagonal structure. Simplicity in the operation, rapidity, high yields, low cost, mild reaction conditions, catalyst with low loading, evading the usage of toxic change metals, stability, and the catalyst reusability are the main advantages of the proposed protocol.
\end{abstract}

Keywords: Nano-catalyst; Mesoporous material; SBA-15; Tetrahydrobenzo [b] pyrans; Green chemistry.

(C) 2020 by the authors. This article is an open-access article distributed under the terms and conditions of the Creative Commons Attribution (CC BY) license (https://creativecommons.org/licenses/by/4.0/).

\section{Introduction}

In recent years, the development of green protocols in the chemical and industrial processes has attracted great attention among the various research groups all over the world. The heterogeneous catalysts compared to the homogeneous ones, can offer remarkable advantages according to the reusability and stability in the chemical reactions [1-4]. Therefore, the design of a heterogeneous catalyst with higher activity and efficiency has been directed towards the research and development of new stable supports, complexes, and other catalytic species on nanostructured materials. Due to the higher surface area and thermal stability of the silica-based mesoporous materials compared to other nano-structures, they are the most attractive for such purposes [5-8]. Silica-based mesoporous materials are appropriate to be functionalized owing to the accessibility of the functional hydroxyl groups [9-11]. SBA-15, as 
mesoporous silica with 2D, ordered channels, and higher stability compared to MCM-types, is an excellent candidate for the different types of catalytic applications. Silica-based mesoporous materials such as SBA-15 have opened an active area in the scientific research and organic synthesis for their use as catalyst-immobilization matrixes [12-15].

These materials display a large specific surface area, narrow pore-size distribution in between two to ten nm, tunable pore size, thermal, chemical, and mechanical stability, highly uniform pore distribution, high adsorption capacity, and an ordered porous network for the fast diffusion and easy access of the substrates and reaction products-especially, SBA-type materials that possess more silanol groups, larger pore sizes, and thicker walls. The silanol functionalization groups on the surface of the mesoporous materials mainly enhance their catalytic ability in the organic reactions [16-19].

Nowadays, the development of environmentally friendly and efficient procedures for the synthesis of interesting biological compounds has been a major issue in academic and industrial researches [16]. Multicomponent reactions (MCRs) have appeared as an important and attractive research area in the organic and medicinal chemistry [20]. MCR methodologies can improve the atom economy and offer efficiency and diversity in the synthesis of the complex molecules, particularly heterocyclic compounds, in a fast and often simple procedure. In such reactions, three or even a lot of reactants gather together in a single response vessel to make the new products that have specified portions of all the components. From the environmental and economic viewpoints, MCRs are well known as valuable tools for the preparation of structurally diverse drug-like compounds [16, 21-24].

Also, numerous organic reactions have been done in the water as a green solvent and reaction medium. It has several advantages, such as abundance, availability, non-polluting nature, inexpensive, and safety $[16,21,25,26]$. Recently, tetrahydro benzo [b] pyrans have attracted great attention due to their biological and pharmacological properties [27-29]. Furthermore, they are the structural unit of many natural products, which are generally found in the comestible fruits and vegetables [27]. These compounds have various properties such as anti-tumoral, anticoagulant, anticancer, anti-HIV, spasmolytic, antioxidant, diuretic, and antianaphylactic activity [27, 30, 31]. Also, some 2-aminotetrahydropyrans have been reported as suitable biological, cosmetics, and photoactive materials (Fig. 1) [30, 32, 33]. Due to the distinct aforementioned properties of $4 \mathrm{H}$-pyrans, different procedures have been reported for the synthesis of $4 \mathrm{H}$-pyrans in the presence of several catalysts such as SBPPSP [33], $\mathrm{SnCl}_{2} / \mathrm{Nano} \mathrm{SiO}_{2}$ [34],TSA, Nano-TiO2/H14[NaP5W30O110] [35], Nano-ZnO [36], [HMIM]C(CN) 3 [37], TFE [38], Supported-KF [39], $\mathrm{Na}_{2} \mathrm{CO}_{3}$ [26], Urea [40], [ $\gamma-\mathrm{Fe}_{2} \mathrm{O}_{3} @ \mathrm{HAp}$ $\mathrm{Si}\left(\mathrm{CH}_{2}\right)_{3} \mathrm{AMP}$ ] [32], Nanozeolit [41], $\mathrm{Fe}_{3} \mathrm{O}_{4} @ \mathrm{SiO}_{2}$-imid-PMA [42], Aminopropylated silica gel [43] DBSA [44], potassium phthalimide (POPI) under mechanochemical ball-milling conditions [45], Borax, [BMIm] $\mathrm{BF}_{4}$ [25], $\mathrm{K}_{3} \mathrm{PO}_{4}$ [44]. However, some limitations such as toxic or expensive catalysts, reagents, and solvents, high catalyst loading, harsh reaction conditions, the use of heavy metals, low yields, long reaction times, and tedious work-up procedures are associated with many of the reported catalytic methods for the synthesis of 4H-pyran derivatives. Moreover, in many of the proposed methods, catalysts are not recyclable.

Therefore, the development of a green and efficient process in order to the synthesis of $4 \mathrm{H}$-pyrans is of great importance to overcome these drawbacks. There is no previous report on the use of 1, 3, 5-tris (2-hydroxyethyl) isocyanurate (THEIC) for the functionalization and modification of SBA-15. The heteroaromatic isocyanurate ring of THEIC has three flexible and nonpolar alkyl arms and is well known for its binding ability to the transition metals. 
Furthermore, it is thermally very stable and is used to enhance the physical properties of a wide variety of polyurethanes, polyureas, and polyesters as coating materials in the commercial systems. These unique properties, as well as other significant properties associated with SBA15, make 1, 3, 5-tris (2-hydroxyethyl) isocyanurate functionalized SBA-15 (SBA-15-THEIC (1), Scheme 1) as a promising nanomaterial, catalyst or support depending on the used conditions compared to the other modified SBA-15 materials. As part of our interest in the developing new eco-friendly, efficient, and green methodologies and explore the application of isocyanurate functionalized materials in different fields as well as MCRs, we herein will report catalytic activity of the THEIC functionalized SBA-15 (1) nanomaterial as a novel, green, reusable, and highly effective heterogeneous nano-catalyst for the one-pot threecomponent synthesis of tetrahydro benzo [b] pyran derivatives under the reflux conditions in water (Scheme 1).<smiles>CC1(C)CC(=O)C2=C(C1)OC(N)=C(C#N)C2Br</smiles><smiles></smiles>

$$
\begin{aligned}
& \mathrm{X}=\mathrm{O}-\mathrm{S} \text { and } \mathrm{NH} \\
& \text { (anticancer } \\
& \text { and antibacterial) }
\end{aligned}
$$
(antibacterial)<smiles></smiles>

$$
\begin{gathered}
\mathrm{X}=\mathrm{O}-\mathrm{S} \text { and } \mathrm{NH} \\
\text { (anticancer } \\
\text { and antibacterial) }
\end{gathered}
$$<smiles>CC1=C(N)Oc2c(ccc3ccccc23)C1Br</smiles>

$\mathrm{Ar}=3-\mathrm{NO} 2-\mathrm{C} 6 \mathrm{H} 4$

or

Pyridyl (anti-rheumatic)

Figure 1. Selected examples of biologically and pharmacologically active $4 \mathrm{H}-$ pyrans

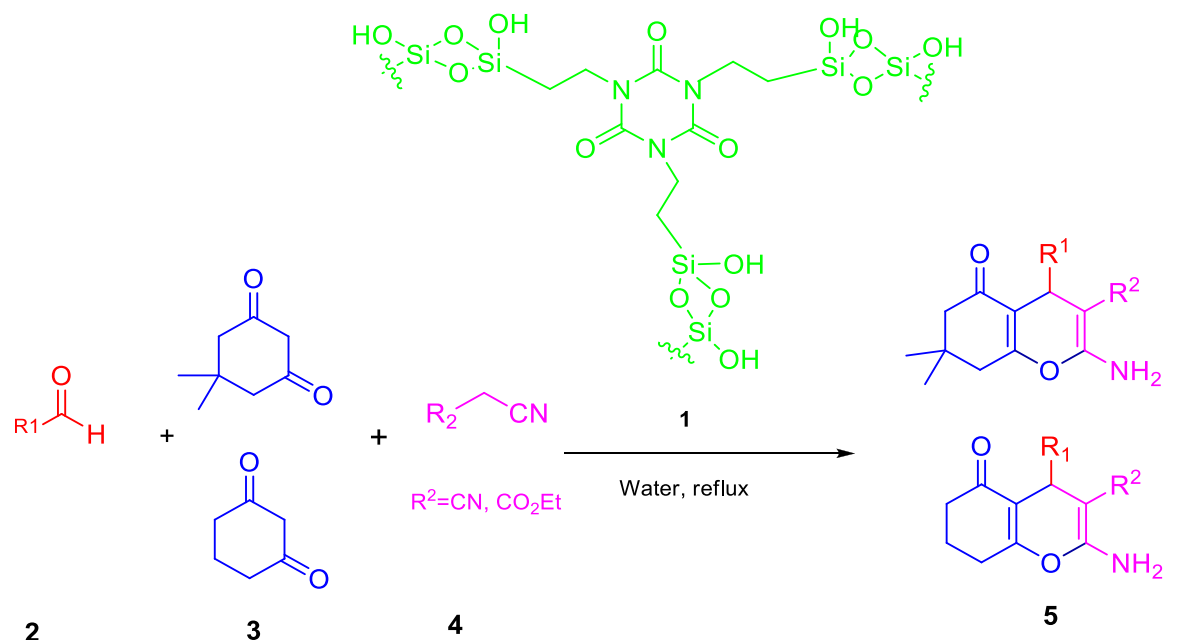

Scheme 1. One-pot three-component reaction of aldehydes, enolizable compounds, and malononitrile catalyzed by THEIC functionalized SBA-15 (1) nanomaterial.

\section{Materials and Methods}

\subsection{General.}

All chemicals were purchased from Sigma Aldrich and used as received. IR spectra were recorded on a Shimadzu FT-IR-8400S spectrophotometer in the $\mathrm{KBr}$ pellet. The development of the responses was evaluated by TLC using Merck $0.2 \mathrm{~mm}$ silica gel 60 F-254 Al-plates. Melting points were determined in the capillary tubes in the Electrothermal 9100 
apparatus. Transmission electron microscopy (TEM) images were obtained using EM10C-100 $\mathrm{kV}$ of Zeiss Company, Germany. Scanning electron microscopy (SEM) images were collected with a sigma of Zeiss Company, Germany. 1H NMR (500 MHz) spectra were obtained using a Bruker DRX-500 AVANCE spectrometer in DMSO at ambient temperature. The BET specific surface area of the catalyst was obtained using equipment ASAP 2020 micromeritics, and the ultrasonic probe used is TOPSONICS $(20 \mathrm{kHz}-400 \mathrm{~W})$ model.

2.2. General process for the synthesis of 1, 3, 5-Tris (2-hydroxyethyl) isocyanurate functionalized SBA-15.

In a traditional synthesis procedure, $2 \mathrm{~g}$ of the Pluronic $\mathrm{P} 123$ block copolymer and $\mathrm{HCl}$ solution $(2 \mathrm{M})$ were stirred at $40{ }^{\circ} \mathrm{C}$ until P123 completely dissolved and the homogenous mixture observed. Afterward, $4.50 \mathrm{~g}$ TEOS was added slowly to the mixture and was stirred for $24 \mathrm{~h}$. Subsequently, the obtained mixture was transferred into the Teflon autoclave for hydrothermal treatment and heated at $100{ }^{\circ} \mathrm{C}$ for $24 \mathrm{~h}$. The resulted gel was filtered, washed, and dried at $100{ }^{\circ} \mathrm{C}$ for $12 \mathrm{~h}$. Finally, template removal carried out by calcination for $6 \mathrm{~h}$ at 540 ${ }^{\circ} \mathrm{C}$. To modification of the mesoporous SBA-15, $1 \mathrm{mmol}$ of 1, 3, 5-tris (2-hydroxy ethyl) isocyanurate, and $3 \mathrm{mmol}$ of 4-toluenesulfonyl chloride were mixed in a test tube in the acetone media. The obtained mixture was placed in an ultrasonic probe at $60^{\circ} \mathrm{C}$ for $1 \mathrm{~h}$. In the next step, $261 \mathrm{mg}$ of SBA-15 was added to the test tube, and the reaction mixture was syndicated at 60 ${ }^{\circ} \mathrm{C}$ for $1.5 \mathrm{~h}$. The white solid was achived, filtered, and dried under the vacuum.

\subsection{General process for the synthesis of 2-amino-4H-chromene derivatives in the water.}

A mixture of aldehydes (2,1 mmol), dimedone or 1, 3-cyclohexanedione $(3,1 \mathrm{mmol})$, malononitrile or ethyl cyanoacetate $(4,1 \mathrm{mmol})$, and 1, 3, 5-Tris (2-hydroxyethyl) isocyanurate functionalized SBA-15 (10 mg) was added to a 50-mL round-bottom flask equipped with a magnetic bar and condenser, and the mixture reaction was stirred under the reflux conditions in the $3 \mathrm{ml}$ of water for the mentioned time shown in Tables 2 and 3, respectively. The progress of the reaction was monitored by TLC as well as precipitating out of the products from the reaction mixture. After completion of the reaction, the solvent was evaporated under the reduced pressure. Then $5 \mathrm{~mL}$ of $\mathrm{EtOH}$ was added to the combination to simplify the separation of the heterogeneous catalyst during the recrystallization from EtOH to give pure products. All of the compounds were characterized by $1 \mathrm{H}-\mathrm{NMR}$, IR, and melting point data.

\subsection{Selected spectroscopic data.}

2-Amino-4-(4-chlorophenyl)-7,7-dimethyl-5-oxo-5,6,7,8-trtrahydro-4H-chromene-3carbonitrile(5a): IR (KBr) 3379,3180,2189,1676,1635,1365,1215 cm-1; 1H-NMR (500 MHz, DMSO-d6) $\delta=0.95$ (s, 3H, CH3), 1.11 (s, 3H, CH3), 2.20 (d, J=16.05 Hz, 1H), 2.30 (d, J=16.05 $\mathrm{Hz}, 1 \mathrm{H}), 2.50$ (s, 2H, CH2), 4.38 (s, 1H, CH), 7.05 (s, br, 2H, NH2), 7.18 (d, J=8.25 Hz, 2H, Ar), 7.36 (d, J= 8.25 Hz, 2H, Ar). 2-Amino-4-(4-hydroxy-3-methoxyphenyl)-7,7-dimethyl-5oxo-5,6,7,8-tetrahydro-4H-chromene-3-carbonitrile (4g): IR (KBr) 3496, 3402, 3323, 3253, 2192, 1676, 1654, 1602, 1367, 1211cm-1; 1H-NMR (250 MHz, DMSO-d6) $\delta=1.00$ (s, 3H), $1.06(\mathrm{~s}, 3 \mathrm{H}), 2.08(\mathrm{~d}, \mathrm{~J}=16.25 \mathrm{~Hz}, 1 \mathrm{H}) 2.23(\mathrm{~d}, \mathrm{~J}=16.25 \mathrm{~Hz}, 1 \mathrm{H}), 2.54(\mathrm{~m}, 2 \mathrm{H}), 3.74(\mathrm{~s}, 3 \mathrm{H})$, $4.10(\mathrm{~s}, 1 \mathrm{H}), 6.53(\mathrm{~m}, 1 \mathrm{H}), 6.81(\mathrm{~m}, 2 \mathrm{H}), 6.97$ (s, 2H), $8.90(\mathrm{~s}, 1 \mathrm{H})$. 


\section{Results and Discussion}

The SBA-15 mesoporous silica was synthesized according to the described procedure by Shylesh and Singh [36]. The obtained catalyst was then characterized using various techniques including transmission electron microscopy (TEM), scanning electron microscopy (SEM), Fourier transforms infrared (FTIR) spectroscopy, and BET surface area analysis. The IR spectrum of THEIC functionalized SBA-15 (1) shows the presence of organic functional groups in the material framework. Indeed, the observed peaks at 2927 and $2850 \mathrm{~cm}-1$ are assigned to the $\mathrm{C}-\mathrm{H}$ stretching of aliphatic moieties. Moreover, the peak which has been appeared at $1699 \mathrm{~cm}-1$ is qualified for the widening vibrations of the isocyanurate ring. On the other hand, THEIC-SBA-15 (1) showed peak at $1080 \mathrm{~cm}-1$ corresponding to the asymmetric and symmetric vibrations of $\mathrm{Si}-\mathrm{O}$ (siloxane) bonds. The broad peak appeared about 3200-3600 $\mathrm{cm}-1$ is attributed to $\mathrm{O}-\mathrm{H}$ bonds of the silanol groups.

The surface area and pore size distribution were calculated using BET and BJH methods, respectively (Fig. 2). The N2-sorption isotherms indicated that the pore sizes of all samples are in the mesoporous range. The materials exhibited a type IV isotherm pattern with H1 hysteresis loops, which are characteristics of the mesoporous structure. This mesoporous material [THEIC-SBA-15 (1)] showed a specific surface area close to $832 \mathrm{~m} 2 / \mathrm{g}$, volume pore $\approx 1.08 \mathrm{~cm} 3 / \mathrm{g}$, and average pore diameter: $5.35 \mathrm{~nm}$ (Fig. 3 ).

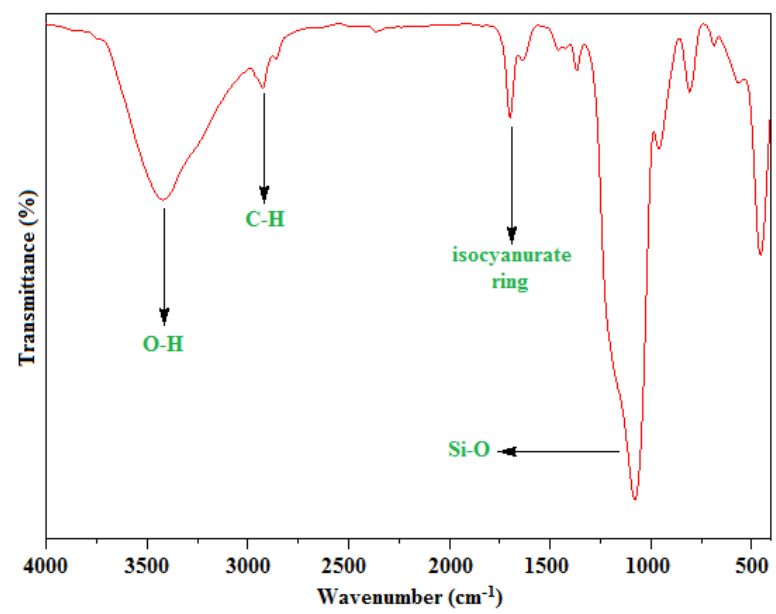

Figure 2. FT-IR spectrum of 1, 3, 5-Tris (2-hydroxyethyl) isocyanurate functionalized SBA-15(THEIC functionalized SBA-15).
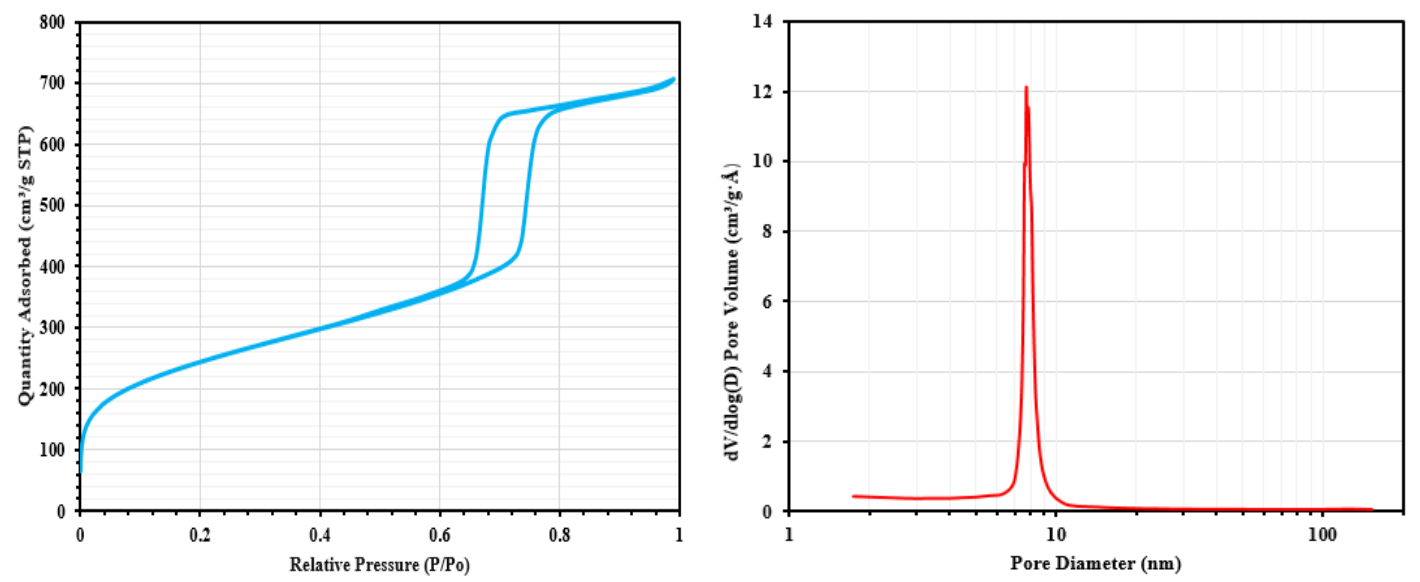

Figure 3. BET \& BJH analyses of the (THEIC functionalized SBA-15) nano-catalyst.

TEM images demonstrated that the mesostructured THEIC-SBA-15 (1) exhibits ordered hexagonal structure (Fig. 4). Moreover, the comparison SEM images of SBA-15 and 
THEIC-SBA-15 indicated the surface modification, the morphology of a sample, and nanoparticles. Also, the morphology of the sample was saved without noteworthy change during the modification process (Fig. 5).

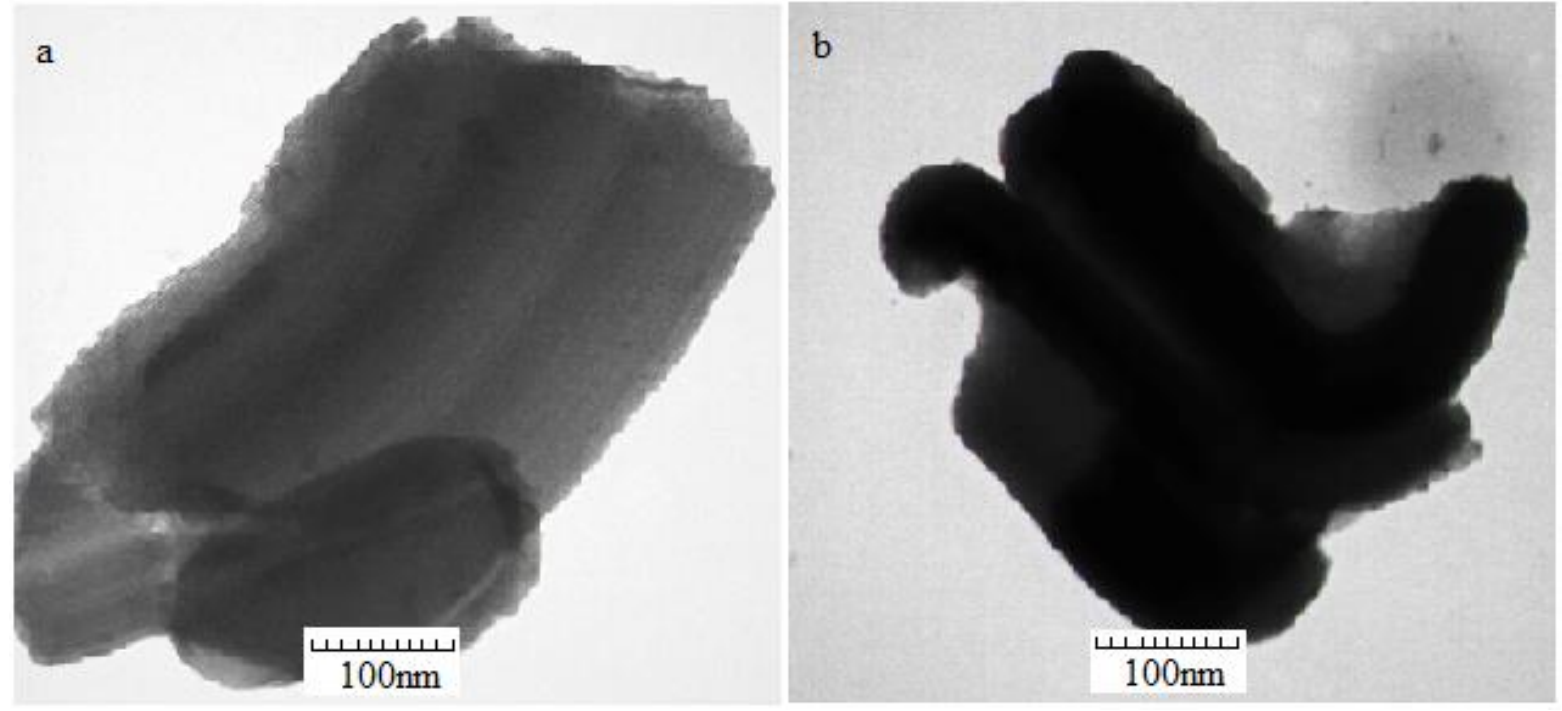

Figure 4. TEM images of a) SBA-15, and b) THEIC-SBA-15.

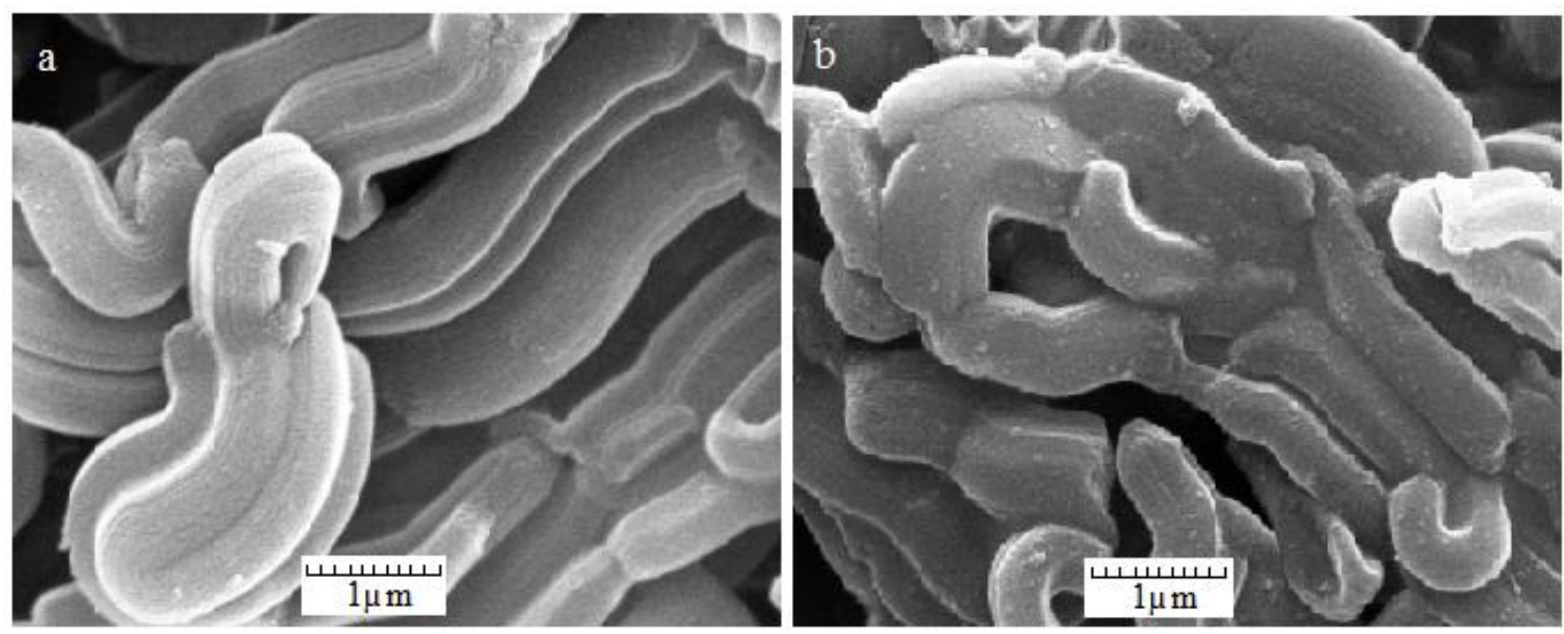

Figure 5. SEM images of a) SBA-15, and b) THEIC-SBA-15.

Table 1. Optimization of the one-pot three-component reaction of dimedone, 4-chlorobenzaldehyde, and malononitrile under various conditions.

\begin{tabular}{c|c|c|c|c|c} 
Entry & $\begin{array}{c}\text { Amount of } \\
\text { Catalyst (mg) }\end{array}$ & Solvent & $\begin{array}{c}\text { Temp } \\
\left({ }^{\circ} \mathbf{C}\right)\end{array}$ & $\begin{array}{c}\text { Time } \\
(\mathbf{m i n})\end{array}$ & $\begin{array}{c}\text { Yield } \\
(\mathbf{\%})\end{array}$ \\
\hline $\mathbf{1}$ & - & - & 100 & 240 & 50 \\
\hline $\mathbf{2}$ & 5 & $\mathrm{H}_{2} \mathrm{O}$ & Reflux & 39 & 80 \\
\hline $\mathbf{3}$ & 10 & $\mathrm{H}_{2} \mathrm{O}$ & Reflux & 24 & 90 \\
\hline $\mathbf{4}$ & 15 & $\mathrm{H}_{2} \mathrm{O}$ & Reflux & 23 & 90 \\
\hline $\mathbf{5}$ & 10 & $\mathrm{H}_{2} \mathrm{O}$ & 60 & 50 & 75 \\
\hline $\mathbf{6}$ & 10 & $\mathrm{Aceton}$ & Reflux & 50 & 50 \\
\hline $\mathbf{7}$ & 10 & EtOH & Reflux & 50 & 30 \\
\hline $\mathbf{8}$ & 10 & $\mathrm{CCl}_{4}$ & Reflux & 50 & 60 \\
\hline $\mathbf{9}$ & 10 & $\mathrm{DMSO}$ & Reflux & 95 & 40 \\
\hline $\mathbf{1 0}$ & 10 & $\mathrm{CHCl}_{3}$ & Reflux & 245 & 45 \\
\hline $\mathbf{1 1}$ & 10 & - & - & 40 & 55
\end{tabular}

To examine the catalytic activity of 1, 3, 5-Tris (2-hydroxyethyl) isocyanurate functionalized SBA-15 (1) and finding the optimal conditions, the three-component reaction and heteroannulation of 4-chlorobenzaldehyde $(2 \mathrm{a})$, dimedone $(3 \mathrm{a}, \mathrm{pKa}=5.23)$ and 
malononitrile (4) (1:1:1 molar ratio) was studied as the model reaction. The results have been summarized in Table 1.

Initially, the effect of temperature, type of solvent, and amount of the loaded catalyst was examined on the model reaction. Maximum 50\% of the desired product (2-amino-4-(4chlorophenyl)-3-cyano-7,7-dimethyl-5-oxo-5,6,7,8-tetrahydro-4H-chromene) (5a) was isolated under the solvent-free and catalyst-free conditions even at $100{ }^{\circ} \mathrm{C}$ after 4 hours (entry 1). Remarkably, it was detected that the use of $5 \mathrm{mg}$ of 1, 3, 5-Tris (2-hydroxyethyl) isocyanurate functionalized SBA-15 (1) as a catalyst, significantly enhanced the production of the wanted product (5a) under the reflux conditions in the water (entry 2). Increasing of the loaded catalyst to $10 \mathrm{mg}$, afforded higher produce of the wanted product (5a) in the shorter reaction time under similar conditions (entry 3 ). However, further increasing the amount of the loaded catalyst had no significant impact on the yield and reaction time (entry 4). Moreover, the desired product was obtained in lower yield and longer reaction time at $60{ }^{\circ} \mathrm{C}$ compared to the reflux temperature in $\mathrm{H} 2 \mathrm{O}$ (entry 5). On the other hand, lower yields of the desired product (5a) were obtained, when the model reaction was investigated using $10 \mathrm{mg}$ catalyst loading of THEIC-SBA-15 (1) in other solvents such as acetone, EtOH, CCl4, DMSO, $\mathrm{CHCl} 3$, under the reflux conditions (entries 6-10). Finally, the desired product (5a) was obtained in the lower yield when the reaction carried out in Ball-milling under the solvent-free conditions (entry 11). As a result, we suggested that the $\mathrm{H}_{2} \mathrm{O}$ is an effective and green solvent; also, reflux conditions and $10 \mathrm{mg}$ of catalyst loading of THEIC-SBA-15 (1) were selected as the optimal conditions for the synthesis of $4 \mathrm{H}$-chrome derivatives.

To obtain the optimized reaction conditions, different derivatives of 2-amino-3-cyano5-oxo-5,6,7,8-tetrahydro-4H-chromene (5a-k) were prepared under the optimal reaction conditions (1, 3, 5-Tris (2-hydroxyethyl) isocyanurate functionalized SBA-15 loading of 10 $\mathrm{mg}$ in $\mathrm{H} 2 \mathrm{O}$ under the reflux conditions) using various aromatic carbocyclic, heterocyclic or $\alpha$, $\beta$-unsaturated aldehydes (2a-1) in high to excellent yields. Furthermore, when 1,3cyclohexanedione $(3 \mathrm{~b}, \mathrm{pKa}=5.26)$ was used as the enolizable component, the corresponding 2-amino-3-cyano-5-oxo-5,6,7,8-tetrahydro-4H-chromene derivatives (51-r) were also achieved in high to admirable yields (see Table2). After completion of the reaction (monitored by TLC), the catalyst 1 was easily isolated from the reaction mixture by the simple filtration.

The obtained results (Table 2) clearly shows that the desired products (5) were prepared with excellent yield under the optimized conditions in the short reaction times. Moreover, the rate of reactions was considerably influenced by the nature of the substituents on the aromatic ring of the aldehydes. Hence, aromatic aldehydes having electron-donating groups required the longer reaction time compared to the electron-withdrawing groups under similar conditions (Tables 2 and 3). These findings imply that the nucleophilic attack of the corresponding imineketene resonance form of malononitrile (4') to the activated aldehydes containing withdrawing groups occurs faster than ones having the electron-donating groups (Scheme 2). Consequently, corresponding Knoevenagel intermediates (III) for the aldehydes containing withdrawing groups will be formed faster. Furthermore, cinnamaldehyde (2j), furfural (2i), and thiophene2-carbaldehyde ( $2 \mathrm{~h})$, which are susceptible to polymerization under the acidic conditions, reacted under optimal reaction conditions to afford the corresponding products, as well as, due to the lower reactivity of the ethyl cyanoacetate, the desired product was obtained in the longer reaction time compared to malononitrile (compound $5 \mathrm{k}$ ). 
Table 2. Synthesis of derivatives of 2-amino-5-oxo-5, 6, 7, 8-tetrahydro-4H-benzo[b] pyran (5) via condensation of dimedone or 1, 3-cyclohexanedione, different aldehydes and malononitrile or ethyl

\begin{tabular}{|c|c|c|c|c|c|c|c|c|}
\hline Entry & R-CHO & $\begin{array}{c}\text { Carbon } \\
\operatorname{acid}\left(\mathbf{R}^{2}\right)\end{array}$ & $\begin{array}{l}\text { Product } \\
(5)\end{array}$ & $\begin{array}{l}\text { Time } \\
(\text { min) }\end{array}$ & $\begin{array}{c}\text { Yield } \\
(\%)\end{array}$ & $\begin{array}{c}\text { Mp (Obsd) } \\
\text { (C) }\end{array}$ & $\begin{array}{c}\text { Mp (lit) } \\
\text { ( C) }\end{array}$ & Reference \\
\hline $\mathbf{1}$ & $4-\mathrm{ClC}_{6} \mathrm{H}_{4}(\mathbf{2 a})$ & $\mathrm{CN}$ & $5 a$ & 24 & 92 & 206-209 & $207-209$ & [46] \\
\hline 2 & $3-\mathrm{NO}_{2}-\mathrm{C}_{6} \mathrm{H}_{4}(2 \mathrm{c})$ & $\mathrm{CN}$ & $5 \mathrm{c}$ & 20 & 95 & $212-214$ & $214-216$ & [47] \\
\hline 3 & $\mathrm{C}_{6} \mathrm{H}_{6}(2 \mathrm{~d})$ & $\mathrm{CN}$ & $5 \mathrm{~d}$ & 29 & 93 & $227-231$ & $226-228$ & [46] \\
\hline 4 & $4-\mathrm{MeOC}_{6} \mathrm{H}_{4}(2 \mathrm{f})$ & $\mathrm{CN}$ & $5 \mathrm{f}$ & 29 & 88 & $200-203$ & $198-200$ & [46] \\
\hline 5 & Vanillin $(2 \mathrm{~g})$ & $\mathrm{CN}$ & $5 \mathrm{~g}$ & 38 & 92 & $230-234$ & $230-238$ & [48] \\
\hline 6 & 2-Thienyl (2h) & $\mathrm{CN}$ & $5 \mathrm{~h}$ & 28 & 94 & $209-214$ & $210-212$ & [49] \\
\hline 7 & 2-Furfural (2i) & $\mathrm{CN}$ & $5 \mathrm{i}$ & 29 & 95 & $220-224$ & $220-223$ & [50] \\
\hline 8 & Cinnamaldehyde (2j) & $\mathrm{CN}$ & $5 \mathrm{j}$ & 30 & 90 & $180-183$ & $182-184$ & [51] \\
\hline 9 & $4-\mathrm{ClC}_{6} \mathrm{H}_{4}(2 \mathrm{a})$ & COOEt & $5 \mathrm{k}$ & 60 & 80 & $150-154$ & $153-154$ & [48] \\
\hline 10 & $4-\mathrm{ClC}_{6} \mathrm{H}_{4}(2 \mathrm{a})$ & $\mathrm{CN}$ & 51 & 31 & 92 & $224-228$ & $226-230$ & [49] \\
\hline 11 & $4-\mathrm{NO}_{2}-\mathrm{C}_{6} \mathrm{H}_{4}(2 \mathrm{~b})$ & $\mathrm{CN}$ & $5 \mathrm{~m}$ & 23 & 92 & $231-235$ & $234-236$ & [52] \\
\hline 12 & $\mathrm{C}_{6} \mathrm{H}_{6}(2 \mathrm{~d})$ & $\mathrm{CN}$ & 50 & 34 & 90 & $235-239$ & $239-241$ & [53] \\
\hline 13 & $4-\mathrm{HOC}_{6} \mathrm{H}_{4}(2 \mathrm{e})$ & $\mathrm{CN}$ & $5 q$ & 37 & 90 & $232-236$ & $234-236$ & [53] \\
\hline 14 & 2-Furfural (2i) & $\mathrm{CN}$ & $5 r$ & 35 & 89 & $232-236$ & 234-235 & [49] \\
\hline 15 & $2-\mathrm{ClC}_{6} \mathrm{H}_{4}(2 \mathrm{k})$ & $\mathrm{CN}$ & $5 n$ & 30 & 95 & $208-213$ & $210-212$ & [52] \\
\hline 16 & $4-\mathrm{MeC}_{6} \mathrm{H}_{4}(2 \mathrm{l})$ & $\mathrm{CN}$ & $5 p$ & 35 & 85 & $220-226$ & $223-225$ & [53] \\
\hline
\end{tabular}

Recyclability of the catalyst is another important aspect of this efficient, non-toxic, and eco-friendly heterogeneous nano-catalyst. In this part of the manuscript, the recycling of the catalyst was examined in the model reaction. The nano-catalyst was separated after completion of the reaction and washed with some ethanol, then dried in the oven at $70{ }^{\circ} \mathrm{C}$. It has been shown that the THEIC-SBA-15 (1) could be recovered and reused at least three times in the subsequent runs without significant loss in its catalytic activity (Fig. 6).

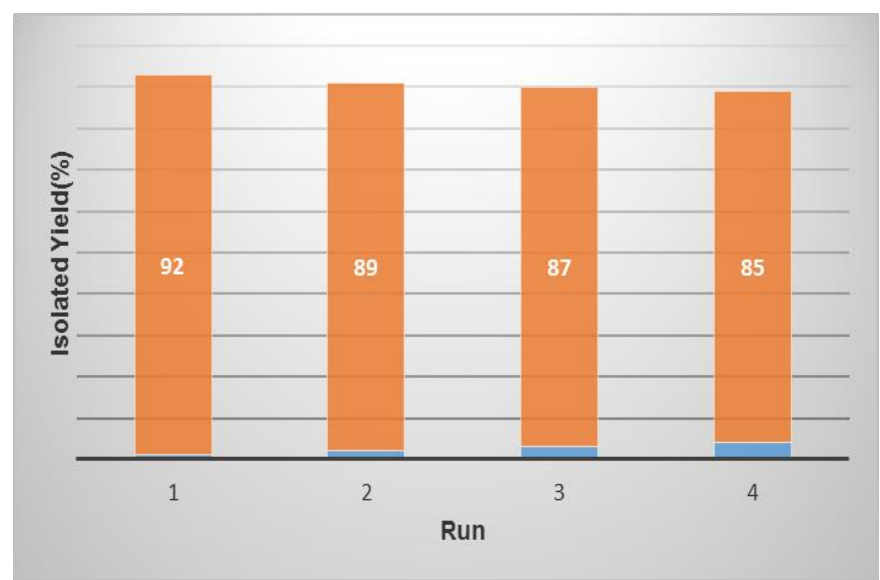

Figure 6. Reusability of 1, 3, 5-Tris (2-hydroxyethyl) isocyanurate functionalized SBA-15 (1) as nano-catalyst for the synthesis of tetrahydrobenzo $[b]$ pyran.

Table 3. Comparison of the catalytic efficiency of THEIC-SBA-15 (1) with the other reported catalysts for the

\begin{tabular}{c|c|c|c|c|c|c}
\multirow{2}{*}{ Entry } & Catalyst & Solvent & $\begin{array}{c}\text { Temp } \\
(\boldsymbol{C})\end{array}$ & $\begin{array}{c}\text { Time } \\
(\boldsymbol{m i n})\end{array}$ & $\begin{array}{c}\text { Yield } \\
(\boldsymbol{\%})\end{array}$ & Reference \\
\hline $\mathbf{1}$ & Borax & EtOH & Reflux & 10 & 82 & {$[44]$} \\
\hline $\mathbf{2}$ & Nano-ZnO & Water & 80 & 30 & 95 & {$[37]$} \\
\hline $\mathbf{3}$ & Aminopropylated silica gel & Water & 70 & 90 & 92 & {$[44]$} \\
\hline $\mathbf{4}$ & Urea & Water-EtOH & r.t & $7 \mathrm{~h}$ & 93 & {$[32]$} \\
\hline $\mathbf{5}$ & Nano-TiO $_{2} / \mathrm{H}_{14}\left[\mathrm{NaP}_{5} \mathrm{~W}_{30} \mathrm{O}_{110}\right]$ & EtOH-US & 40 & 15 & 94 & {$[36]$} \\
\hline $\mathbf{6}$ & Alumina supported KF & EtOH & Reflux & 120 & 92 & {$[26]$}
\end{tabular}

To demonstrate the efficiency of the present procedure for the synthesis of different 4H-pyran derivatives, the obtained results in Table 3 are compared with those of the previously 
reported procedures in the literature. THEIC-SBA-15 (1) shows higher catalytic activity in comparison to several of the others in terms of catalyst loading, evading the usage of toxic transition metals, corrosive reagents, or toxic solvents, product yield and required reaction time.

The proposed mechanism for the one-pot three-component reaction of aldehydes, different 1,3-dicarbonyl compounds, and malononitrile catalyzed by THEIC-SBA-15 (1) is shown in Scheme 2. It can be offered that the hydroxyl groups on the surface of THEIC-SBA15 (1) are responsible for the initial activation of both carbonyl groups of aldehydes (2) and malononitrile (4) by hydrogen bonding to the facilitate nucleophilic addition (Knoevenagal condensation) of the corresponding imine-ketene resonance form of malononitrile (4') on the activated aldehydes (I) and formation of intermediate (II). Then in the next step, the cyanocinnamonitrile intermediate was formed with the elimination of water molecule (III). The THEIC-SBA-15 (1) is also can increase enol form (3'), the concentration of 1,3-dicarbonyls and subsequent Michael addition to form the intermediate (IV) followed by heteroannulation of this obtained intermediate and its final tautomerization in the presence of THEIC-SBA-15 (1), as a heterogeneous nano-catalyst, affords the corresponding products 5.

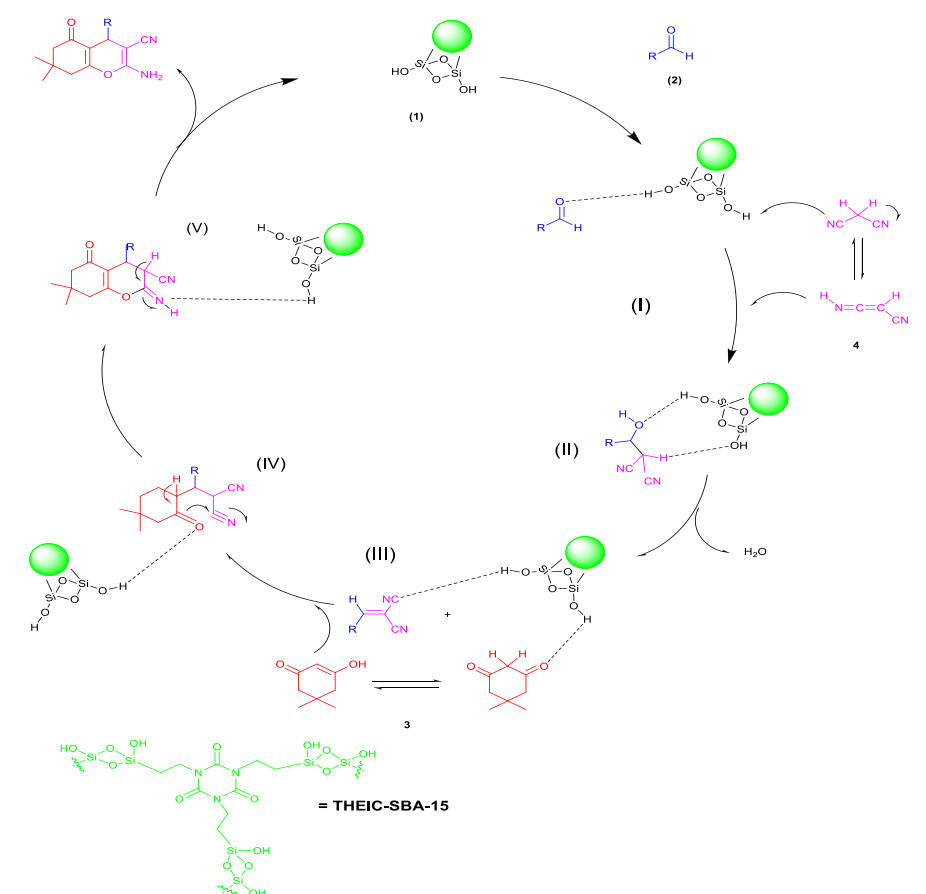

Scheme 2. A plausible mechanism for the one-pot three-component reaction of aldehydes 2 , different 1,3dicarbonyl compounds and malononitrile/ethyl cyanoacetate (4) catalyzed by THEIC-SBA-15 (1) in water.

\section{Conclusions}

In the presented work a green, facile, new environmentally benign, and highly efficient one-pot three-component methodology has been advanced in order to the synthesis of the wide range of pharmaceutically interesting substituted tetrahydro benzo [b] pyrans in the presence of 1,3,5-Tris(2-hydroxyethyl) isocyanurate functionalized SBA-15, as a new and efficient heterogeneous catalyst via one-pot condensation of aldehydes, malononitrile, and dimedone or 1, 3-cyclohexanedione in the water under the reflux condition. This procedure offers several advantages, including high yields, mild reaction conditions, the simplicity of the operation, and short reaction time. Also, this catalyst can be easily recovered and reused for several runs without significant loss of catalytic activity. 


\section{Funding}

There is no financial support.

\section{Acknowledgments}

\section{The authors thank the Research Council of Baqiyatallah University of Medical Sciences and Iran University of Science and Technology for their kind help.}

\section{Conflicts of Interest}

The authors declare no conflict of interest.

\section{References}

1. Selvam, P.; Krishna, N.V.; Viswanathan, B. Architecting mesoporous AlSBA-15: Anoverview on the synthetic strategy. J Indian I Sci 2012, 90, 271-285.

2. Pratap Rao, D. A review on versatile applications of novel Schiff bases and their metal complexes. Lett. Appl. NanoBioScience 2019, 8, 675 -681, https://doi.org/10.33263/LIANBS84.675681.

3. Alirezvani, Z.; Dekamin, M.G.; Valiey, E. New Hydrogen-Bond-Enriched 1,3,5-Tris(2-hydroxyethyl) Isocyanurate Covalently Functionalized MCM-41: An Efficient and Recoverable Hybrid Catalyst for Convenient Synthesis of Acridinedione Derivatives. ACS Omega 2019, 4, 20618-20633, https://doi.org/10.1021/acsomega.9b02755.

4. Fathollahi, M.; Rostamizadeh, S.; Amani, A.M. A Clean, Mild, and Efficient Preparation of Aryl 14H-benzo $[a, j]$ xanthene leuco-dye Derivatives via Nanocatalytic MCM-41-SO3H under Ultrasonic Irradiation in Aqueous Media. Comb Chem High Throughput Screen 2018, 21, 5-13, https://doi.org/10.2174/1386207321666180104111508.

5. Kresge, C.T.; Leonowicz, M.E.; Roth, W.J.; Vartuli, J.C.; Beck, J.S. Ordered mesoporous molecular sieves synthesized by a liquid-crystal template mechanism. Nature 1992, 359, 710-712, https://doi.org/10.1038/359710a0.

6. Ghomi, J.S.; Akbarzadeh, Z. Ultrasonic accelerated Knoevenagel condensation by magnetically recoverable $\mathrm{MgFe} 2 \mathrm{O} 4$ nano-catalyst: A rapid and green synthesis of coumarins under solvent-free conditions. Ultrason Sonochem 2018, 40, 78-83, https://doi.org/10.1016/j.ultsonch.2017.06.022.

7. Ishani, M.; Dekamin, M.G.; Alirezvani, Z. Superparamagnetic silica core-shell hybrid attached to graphene oxide as a promising recoverable catalyst for expeditious synthesis of TMS-protected cyanohydrins. $J$ Colloid Interface Sci 2018, 521, 232-241, https://doi.org/10.1016/j.jcis.2018.02.060.

8. Kasprzak, A.; Bystrzejewski, M.; Poplawska, M. Sulfonated carbon-encapsulated iron nanoparticles as an efficient magnetic nano-catalyst for highly selective synthesis of benzimidazoles. Dalton Trans 2018, 47, 6314-6322, https://doi.org/10.1039/c8dt00677f.

9. Han, Y.; Zhang, D. Ordered mesoporous silica materials with complicated structures. Curr. Opin. Chem. Eng 2012, 1, 129-137, https://doi.org/10.1016/j.coche.2011.11.001.

10. Kiani, F.; Naeimi, H. Ultrasonic accelerated coupling reaction using magnetically recyclable bis (propyl molononitril) Ni complex nano-catalyst: A novel, green and efficient synthesis of biphenyl derivatives. Ultrason Sonochem 2018, 48, 267-274, https://doi.org/10.1016/j.ultsonch.2018.06.001.

11. Mirhosseyni, M.S.; Nemati, F.; Elhampour, A. A Simple and One-pot Synthesis of Tetrahydrobenzo [b] pyrans and Spirooxindoles Catalyzed by H-Fe3O4@ DA-SO3H as an Efficient, Light and Reusable Nanocatalyst. Comb Chem High Throughput Screen 2018, 21, 487-494, https://doi.org/10.2174/1386207321666180817142658.

12. Stevens, W.J.; Lebeau, K.; Mertens, M.; Van Tendeloo, G.; Cool, P.; Vansant, E.F. Investigation of the morphology of the mesoporous SBA-16 and SBA-15 materials. J Phys Chem B 2006, 110, 9183-7, https://doi.org/10.1021/jp0548725.

13. Narkhede, N.; Uttam, B.; Rao, C.P. Calixarene-Assisted Pd Nanoparticles in Organic Transformations: Synthesis, Characterization, and Catalytic Applications in Water for C-C Coupling and for the Reduction of Nitroaromatics and Organic Dyes. ACS omega 2019, 4, 4908-4917, https://doi.org/10.1021/acsomega.9b00095.

14. Pourhasan-Kisomi, R.; Shirini, F.; Golshekan, M. Organic/inorganic Fe3O4@ MCM-41@ Zr-piperazine: an impressive magnetite nano-catalyst for N-tert-butoxycarbonylation of amines. J Nanosci Nanotechnol 2019, 19, 3859-3870, https://doi.org/10.1166/jnn.2019.16291.

15. Rangraz, Y.; Nemati, F.; Elhampour, A. Diphenyl diselenide immobilized on magnetic nanoparticles: A novel and retrievable heterogeneous catalyst in the oxidation of aldehydes under mild and green conditions. J Colloid Interface Sci 2018, 509, 485-494, https://doi.org/10.1016/j.jcis.2017.09.034. 
16. Hazeri, N.; Maghsoodlou, M.T.; Mir, F.; Kangani, M.; Saravani, H.; Molashahi, E. An efficient one-pot three-component synthesis of tetrahydrobenzo[b]pyran and 3,4-dihydropyrano[c]chromene derivatives using starch solution as catalyst. Chinese J. Catal 2014, 35, 391-395, https://doi.org/10.1016/s18722067(14)60003-6.

17. Samani, A.; Abdolmohammadi, S.; Otaredi-Kashani, A. A Green Synthesis of Xanthenone Derivatives in Aqueous Media Using TiO2-CNTs Nanocomposite as an Eco-Friendly and Reusable Catalyst. Comb Chem High Throughput Screen 2018, 21, 111-116, https://doi.org/10.2174/1386207321666180219151705.

18. Zindani, D.; Kumar, K. Graphene-based polymeric nano-composites: An introspection into functionalization, processing techniques and biomedical applications. Biointerface Res. Appl. Chem 2019, 9, 3926-3933, https://doi.org/10.33263/briac93.926933.

19. Ulu, A.; Noma, S.A.A.; Koytepe, S.; Ates, B. Magnetic Fe3O4@ MCM-41 core-shell nanoparticles functionalized with thiol silane for efficient l-asparaginase immobilization. Artif Cells Nanomed Biotechnol 2018, 46, 1035-1045, https://doi.org/10.1080/21691401.2018.1478422.

20. Janvier, P.; Sun, X.; Bienayme, H.; Zhu, J. Ammonium chloride-promoted four-component synthesis of pyrrolo[3,4-b]pyridin-5-one. J Am Chem Soc 2002, 124, 2560-7, https://doi.org/10.1021/ja017563a.

21. Climent, M.J.; Corma, A.; Iborra, S. Homogeneous and heterogeneous catalysts for multicomponent reactions. RSC advances 2012, 2, 16-58, https://doi.org/10.1039/C1RA00807B.

22. Zhang, S.; Lu, F.; Ma, X.; Yue, M.; Li, Y.; Liu, J.; You, J. Quaternary ammonium-functionalized MCM-48 mesoporous silica as a sorbent for the dispersive solid-phase extraction of endocrine disrupting compounds in water. J Chromatogr A 2018, 1557, 1-8, https://doi.org/10.1016/j.chroma.2018.05.011.

23. Zheng, X.; Wang, M.; Li, Q. Synthesis and luminescent properties of europium complexes covalently bonded to hybrid materials based on MCM-41 and poly (ionic liquids). Materials (Basel) 2018, 11, 677, https://doi.org/10.3390/ma11050677.

24. Esfahanizadeh, N.; Daneshparvar, P.; Takzaree, N.; Rezvan, M.; Daneshparvar, N. Histologic Evaluation of the Bone Regeneration Capacities of Bio-Oss and MinerOss X in Rabbit Calvarial Defects. Int J Periodont Rest 2019, 39, e219-e227, https://doi.org/10.11607/prd.4181.

25. Dekamin, M.G.; Eslami, M. Highly efficient organocatalytic synthesis of diverse and densely functionalized 2-amino-3-cyano-4H-pyrans under mechanochemical ball milling. Green Chem 2014, 16, 4914-4921, https://doi.org/10.1039/c4gc00411f.

26. Hasaninejad, A.; Jafarpour, N.; Mohammadnejad, M. Synthesis of Benzo[b]pyrane Derivatives Using Supported Potassium Fluoride as an Efficient and Reusable Catalytic System. E- J. Chem 2012, 9, 20002005, https://doi.org/10.1155/2012/494021.

27. Goldmann, S.; Stoltefuss, J. 1,4-Dihydropyridines: Effects of Chirality and Conformation on the Calcium Antagonist and Calcium Agonist Activities. Angew. Chem. Int. Ed 1991, 30, 1559-1578, https://doi.org/10.1002/anie.199115591.

28. Hafez, E.A.A.; Elnagdi, M.H.; Elagamey, A.G.A.; El-Taweel, F.M.A.A. Nitriles in heterocyclic synthesis: novel synsthesis of benzo [c]-coumarin and of benzo [c] pyrano [3, 2-c] quinoline derivatives. Heterocycles 1987, 26, 903-907, https://doi.org/10.1002/chin.198738206.

29. Esfahanizadeh, N.; Yousefi, H. Successful Implant Placement in a Case of Florid Cemento-Osseous Dysplasia: A Case Report and Literature Review. J Oral Implantol 2018, 44, 275-279, https://doi.org/10.1563/aaid-joi-D-17-00140.

30. Balalaie, S.; Sheikh-Ahmadi, M.; Bararjanian, M. Tetra-methyl ammonium hydroxide: An efficient and versatile catalyst for the one-pot synthesis of tetrahydrobenzo[b]pyran derivatives in aqueous media. Catal. Commun 2007, 8, 1724-1728, https://doi.org/10.1016/j.catcom.2007.01.034.

31. Daneshparvar, H.; Sadat-Shirazi, M.S.; Fekri, M.; Khalifeh, S.; Ziaie, A.; Esfahanizadeh, N.; Vousooghi, N.; Zarrindast, M.R. NMDA receptor subunits change in the prefrontal cortex of pure-opioid and multi-drug abusers: a post-mortem study. Eur Arch Psychiatry Clin Neurosci 2019, 269, 309-315, https://doi.org/10.1007/s00406-018-0900-8.

32. Brahmachari, G.; Banerjee, B. Facile and One-Pot Access to Diverse and Densely Functionalized 2-Amino3-cyano-4H-pyrans and Pyran-Annulated Heterocyclic Scaffolds via an Eco-Friendly Multicomponent Reaction at Room Temperature Using Urea as a Novel Organo-Catalyst. ACS Sustain. Chem. Eng 2013, 2, 411-422, https://doi.org/10.1021/sc400312n.

33. Niknam, K.; Borazjani, N.; Rashidian, R.; Jamali, A. Silica-bonded N-propylpiperazine sodium n-propionate as recyclable catalyst for synthesis of 4H-pyran derivatives. Chinese $j$ catal 2013, 34, 2245-2254, https://doi.org/10.1016/s1872-2067(12)60693-7.

34. Safaei-Ghomi, J.; Teymuri, R.; Shahbazi-Alavi, H.; Ziarati, A. SnCl2/nano SiO2: A green and reusable heterogeneous catalyst for the synthesis of polyfunctionalized 4H-pyrans. Chinese Chem Lett 2013, 24, 921925, https://doi.org/10.1016/j.cclet.2013.06.021.

35. Azarifar, D.; Khatami, S.-M.; Zolfigol, M.A.; Nejat-Yami, R. Nano-titania sulfuric acid-promoted synthesis of tetrahydrobenzo[b]pyran and 1,4-dihydropyrano[2,3-c]pyrazole derivatives under ultrasound irradiation. J Iran Chem Soc 2013, 11, 1223-1230, https://doi.org/10.1007/s13738-013-0392-4. 
36. Azarifar, D.; Khatami, S.-M.; Nejat-Yami, R. Nano-titania-supported Preyssler-type heteropolyacid: An efficient and reusable catalyst in ultrasound-promoted synthesis of 4H-chromenes and 4H-pyrano[2,3c]pyrazoles. J Chem Sci 2014, 126, 95-101, https://doi.org/10.1007/s12039-013-0548-X.

37. Hosseini-Sarvari, M.; Shafiee-Haghighi, S. Nano-ZnO as heterogeneous catalyst for three-component onepot synthesis of tetrahydrobenzo[b]pyrans in water. Chem Heterocycl Com 2012, 48, 1307-1313, https://doi.org/10.1007/s10593-012-1137-5.

38. Zolfigol, M.A.; Bahrami-Nejad, N.; Afsharnadery, F.; Baghery, S. 1-Methylimidazolium tricyanomethanide $\{[\mathrm{HMIM}] \mathrm{C}(\mathrm{CN}) 3\}$ as a nano structure and reusable molten salt catalyst for the synthesis of tetrahydrobenzo[b]pyrans via tandem Knoevenagel-Michael cyclocondensation and 3,4dihydropyrano[c]chromene derivatives. J. Mol. Liq 2016, 221, 851-859, https://doi.org/10.1016/j.molliq.2016.06.069.

39. Khaksar, S.; Rouhollahpour, A.; Talesh, S.M. A facile and efficient synthesis of 2-amino-3-cyano-4Hchromenes and tetrahydrobenzo[b]pyrans using 2,2,2-trifluoroethanol as a metal-free and reusable medium. J. Fluor. Chem 2012, 141, 11-15, https://doi.org/10.1016/j.jfluchem.2012.05.014.

40. Guo, R.Y.; An, Z.M.; Mo, L.P.; Wang, R.Z.; Liu, H.X.; Wang, S.X.; Zhang, Z.H. Meglumine: A novel and efficient catalyst for one-pot, three-component combinatorial synthesis of functionalized 2-amino-4Hpyrans. ACS Comb Sci 2013, 15, 557-63, https://doi.org/10.1021/co400107j.

41. Khoobi, M.; Ma'mani, L.; Rezazadeh, F.; Zareie, Z.; Foroumadi, A.; Ramazani, A.; Shafiee, A. One-pot synthesis of $4 \mathrm{H}$-benzo[b]pyrans and dihydropyrano[c]chromenes using inorganic-organic hybrid magnetic nano-catalyst in water. $J$ Mol Catal A Chem 2012, 359, 74-80, https://doi.org/10.1016/j.molcata.2012.03.023.

42. Baghbanian, S.M.; Rezaei, N.; Tashakkorian, H. Nanozeolite clinoptilolite as a highly efficient heterogeneous catalyst for the synthesis of various 2 -amino- $4 \mathrm{H}$-chromene derivatives in aqueous media. Green Chemistry 2013, 15, 3446, https://doi.org/10.1039/c3gc41302k.

43. Esmaeilpour, M.; Javidi, J.; Dehghani, F.; Nowroozi Dodeji, F. A green one-pot three-component synthesis of tetrahydrobenzo[b]pyran and 3,4-dihydropyrano[c]chromene derivatives using a Fe3O4@SiO2-imidPMAn magnetic nano-catalyst under ultrasonic irradiation or reflux conditions. RSC Advances 2015, 5, 26625-26633, https://doi.org/10.1039/c5ra01021g.

44. Joshi, V.M.; Magar, R.L.; Throat, P.B.; Tekale, S.U.; Patil, B.R.; Kale, M.P.; Pawar, R.P. Novel one-pot synthesis of $4 \mathrm{H}$-chromene derivatives using amino functionalized silica gel catalyst. Chinese Chem Lett 2014, 25, 455-458, https://doi.org/10.1016/j.cclet.2013.12.016.

45. Dekamin, M.G.; Eslami, M.; Maleki, A. Potassium phthalimide-N-oxyl: a novel, efficient, and simple organocatalyst for the one-pot three-component synthesis of various 2-amino-4H-chromene derivatives in water. Tetrahedron 2013, 69, 1074-1085, https://doi.org/10.1016/j.tet.2012.11.068.

46. Devi, I.; Bhuyan, P.J. Sodium bromide catalysed one-pot synthesis of tetrahydrobenzo[b]pyrans via a threecomponent cyclocondensation under microwave irradiation and solvent free conditions. Tetrahedron Let 2004, 45, 8625-8627, https://doi.org/10.1016/j.tetlet.2004.09.158.

47. Kazemzad, M.; Yuzbashi, A.A.; Balalaie, S.; Bararjanian, M. Modified SBA-15 as an Efficient Environmentally Friendly Nanocatalyst for One-Pot Synthesis of Tetrahydrobenzo[b]pyrane Derivatives. Synth React Inorg M 2011, 41, 1182-1187, https://doi.org/10.1080/15533174.2011.591646.

48. Rong, L.; Li, X.; Wang, H.; Shi, D.; Tu, S.; Zhuang, Q. Efficient Synthesis of Tetrahydrobenzo[b]pyrans under Solvent-Free Conditions at Room Temperature. Synth. Commun 2006, 36, 2363-2369, https://doi.org/10.1080/00397910600640230.

49. Sun, W.-B.; Zhang, P.; Fan, J.; Chen, S.H.; Zhang, Z.H. Lithium Bromide as a Mild, Efficient, and Recyclable Catalyst for the One-Pot Synthesis of Tetrahydro-4H-Chromene Derivatives in Aqueous Media. Synth. Commun 2010, 40, 587-594, https://doi.org/10.1080/00397910903007079.

50. Sabitha, G.; Arundhathi, K.; Sudhakar, K.; Sastry, B.S.; Yadav, J.S. Cerium(III) Chloride-Catalyzed OnePot Synthesis of Tetrahydrobenzo[b]pyrans. Synth. Commun 2009, 39, 433-442, https://doi.org/10.1080/00397910802378399.

51. Wang, L.M.; Shao, J.H.; Tian, H.; Wang, Y.H.; Liu, B. Rare earth perfluorooctanoate [RE(PFO)3] catalyzed one-pot synthesis of benzopyran derivatives. Fluorine Chem 2006, 127, 97-100, https://doi.org/10.1016/j.jfluchem.2005.10.004.

52. Kumar, S.; Sharma, P.; Kapoor, K.K.; Hundal, M.S. An efficient, catalyst- and solvent-free, four-component, and one-pot synthesis of polyhydroquinolines on grinding. Tetrahedron 2008, 64, 536-542, https://doi.org/10.1016/j.tet.2007.11.008.

53. Nasseri, M.; Sadeghzadeh, S.M. A highly active FeNi3-SiO2 magnetic nanoparticles catalyst for the preparation of $4 \mathrm{H}$-benzo[b]pyrans and Spirooxindoles under mild conditions. J Iran Chem Soc 2013, 10, https://doi.org/10.1007/s13738-013-0243-3. 